\section{RMD Open}

Rheumatic \&

Musculoskeletal Diseases

\title{
It is not just about sex: viewpoints of men with inflammatory arthritis on the overall impact of the disease on their sexual health
}

\author{
Luis Fernando Perez-Garcia (D) , ${ }^{1}$ Esther Röder (D) , ${ }^{1}$ Hester Pastoor, ${ }^{2}$ \\ Johanna M Bolt, ${ }^{2}$ Job van Exel, ${ }^{3}$ Radboud J E M Dolhain ${ }^{1}$
}

To cite: Perez-Garcia LF, Röder E, Pastoor $\mathrm{H}$, et al. It is not just about sex: viewpoints of men with inflammatory arthritis on the overall impact of the disease on their sexual health. RMD Open 2021;7:e001821. doi:10.1136/ rmdopen-2021-001821

- Additional supplemental material is published online only. To view, please visit the journal online (http://dx.doi.org/10. 1136/rmdopen-2021-001821).

Received 14 July 2021 Accepted 10 September 2021

Check for updates

(C) Author(s) (or their employer(s)) 2021. Re-use permitted under CC BY-NC. No commercial re-use. See rights and permissions. Published by BMJ.

${ }^{1}$ Department of Rheumatology, Erasmus MC, University Medical Center, Rotterdam, The Netherlands

${ }^{2}$ Department of Obstetrics and Gynecology, Division of Reproductive Endocrinology and Infertility, Erasmus MC, University Medical Center, Rotterdam, The Netherlands ${ }^{3}$ Erasmus School of Health Policy \& Management, Erasmus University Rotterdam, Rotterdam, The Netherlands

Correspondence to Dr Luis Fernando Perez-Garcia; I.perez@erasmusmc.nl

\section{ABSTRACT}

Objectives Sexual health is defined as a state of physical, emotional, mental and social well-being in relation to sexuality. The impact of inflammatory arthritis (IA) on male sexual health has been mainly studied focusing on erectile function, one of the physical components of sexual health. Our objective was to describe the viewpoints among men with IA in the Netherlands on the overall impact of IA on their sexual health.

Methods Q-methodology, a mixed methods approach to systematically study subjectivity was used. Adult men diagnosed with IA ranked 34 opinion statements about potential impacts of IA on their sexual health and were interviewed. By-person factor analysis was used to identify common patterns in the rankings, which were interpreted as viewpoints. Data from the interviews were used to verify and adjust the interpretations.

Results 30 men (22-77 years) with IA were included. The analysis revealed three viewpoints. Men with the viewpoint 'Arthritis negatively affects my sexual health' experience a dramatic impact on all components of sexual health. In viewpoint 'I am keeping up appearances', IA negatively impacts sexual health but a distinguishing coping mechanism could mask a more serious negative impact. Men with the viewpoint 'I am satisfied with my sexual health" experience no significant impact of IA on their sexual health.

Conclusions We identified three viewpoints on the impact of IA on male sexual health, two revealed a negative influence that goes beyond the physical act of sex. IA can severely affect the emotional, mental and social components of sexual health.

\section{INTRODUCTION}

Sexual health has been defined as a state of physical, emotional, mental and social wellbeing in relation to sexuality. ${ }^{1}$ Despite the fact that sexual health is not merely the absence of disease, dysfunction or infirmity, the impact of inflammatory arthritis (IA) on male sexual health has mainly been studied focusing on

\section{Key messages}

What is already known about this subject?

- Most research on the impact of inflammatory arthritis (IA) on male sexual health has focused on the physical aspect of sexual health, in particular erectile dysfunction. These studies have shown that erectile dysfunction is highly prevalent in this population.

What does this study add?

- Three viewpoints on the impact of IA on male sexual health were described: 'Arthritis negatively affects my sexual health', 'I am keeping up appearances' and 'I am satisfied with my sexual health'.

- These viewpoints demonstrated that the impact of IA goes well beyond the physical aspect of sexual health. Mental, emotional and social components of sexual health can also be negatively affected by IA. Although the effect on sexual health can have significant consequences on patients' lives, this topic was scarcely approached by their healthcare professionals.

How might this impact on clinical practice or future developments?

- Since this study revealed that IA can significantly impact multiple components of male sexual health, this topic cannot be neglected any longer. Therefore, efforts should be made to increase awareness and educate healthcare professionals in rheumatology about this topic.

- Future research should focus on identifying interventions that can result in preventing or reducing the negative impact of IA on male sexual health. The identified viewpoints could be useful for this purpose.

the association of IA with erectile dysfunction (ED).

ED is a highly prevalent comorbidity in men diagnosed with IA $(33 \%-62 \%)$. $^{2}$ Several factors such as inflammation, alterations in the endocrine axis, adverse events of 
medication, disability secondary to disease and comorbidities are thought to be responsible for this association. Although male sexual health goes well beyond erectile function and may be impaired by factors such as fears, emotions and beliefs, the impact of IA on the emotional, mental and social components of sexual health has not yet been comprehensively studied. ${ }^{34}$

In order to be able to help men with sexual health problems due to IA, we first need to identify and understand the impact of IA, not only on the physical component but also on the emotional, mental and social components of sexual health.

These components are difficult to analyse and interpret because of their subjective nature. Questionnaires mainly generate quantitative data and can easily miss relevant subjective information. Focus groups provide qualitative data and have been used to explore sexuality. ${ }^{5}$ Q-methodology combines the strengths of qualitative and quantitative approaches and is a powerful methodology for systematically exploring and explaining patterns in subjectivities (viewpoints, opinions, beliefs) around sensitive topics and identifying consensus and contrasts between them. ${ }^{6}$ Recently, Q-methodology ${ }^{7-9}$ has gained attention from researchers in the medical community and has been used to help us better understand complex topics in medicine such as Human Papillomavirus (HPV) vaccination, palliative care, end-stage renal disease and organ donation. ${ }^{10-13}$ Therefore, Q-methodology can be considered as a suitable method to study the overall impact of IA on male sexual health.

Our objective is to use Q-methodology to describe the viewpoints of adult men with IA concerning the overall impact of IA on their sexual health.

\section{METHODS}

\section{Q-methodology}

Q-methodology combines qualitative and quantitative techniques to empirically study subjectivity. The whole process of a Q-methodology study can be summarised in four stages (see figure 1). ${ }^{7}$ Information on the use of Q-methodology in healthcare research can be found elsewhere. ${ }^{14}$ Furthermore, a checklist to include when reporting a Q-methodology study was included as online supplemental table 1.

\section{Patient and public involvement}

Five male patients diagnosed with IA (four were active members of the research advisory board from the Department of Rheumatology of the Erasmus University Medical Center) were involved in the design of the research question, statements, patient information leaflet and invitation letter. During a pilot study four patients evaluated the statement set and the interview materials. Three patients were involved in the interpretation of the results. We carefully assessed the burden on participating patients. We intend to share the results to participating patients and will appropriately disseminate the results.

\section{Development of statement set}

- Identification of the concourse

- Sampling of statements

- Pilot study

\section{Data collection}

- Selection of participants

- Statement sorting followed up by interview (per participant)

\section{Data analysis and interpretation}

- By-person factor analysis

- Factor interpretation

\section{Description of factors \\ - Comprehensive narrative for each factor}

Figure 1 The stages of Q-methodology study.

\section{Participants}

Men of 18 years or older, diagnosed with IA (rheumatoid arthritis (RA) or polyarticular juvenile idiopathic arthritis (JIA)) were invited to participate by their own rheumatologist. Because our objective was to evaluate the viewpoints of men with IA and the term spondyloarthritis compromises an extensive group of diseases that are associated with a diverse range of extra-articular manifestations (ie, low back pain and psoriatic lesions on the skin) that on their own may negatively impact sexual health, ${ }^{15} 16$ patients diagnosed with spondyloarthritis were excluded. Therefore, in this study, when referring to IA we focus only on the diagnoses of RA and JIA. Participants were recruited between October 2019 and October 2020, mainly from the general rheumatology and the specialised reproductive rheumatology outpatient clinics from the Erasmus University Medical Center, Rotterdam, the Netherlands. As the aim of the Q-methodology is to explore the variety of viewpoints, not to make claims about the percentage of people expressing them, participants were gathered purposively to ensure diversity. Therefore, recruiters were instructed to invite men with different cultural, religious and socioeconomic backgrounds as well as different sexual orientations. Furthermore, they were also instructed to invite participants of all ages ( $\geq 18$ year) who were either recently diagnosed with IA $(<1$ year) or had longer disease duration. To promote diversity, three researchers (LFP-G, ER and RJED) frequently informed recruiters about the progress 
of inclusion of the participants. In a Q-methodology study it has been recommended to aim to include a number of participants that is smaller than the number of statements. ${ }^{7}$ Data collection proceeded until saturation was achieved. This was considered to be the case when at least five participants in each of the specified target groups of patients were interviewed and consecutive interviews revealed no significant new viewpoints as compared with earlier interviews.

\section{Statement set development}

Two researchers (LFP-G and ER) independently collected candidate statements on how IA can affect the various components of male sexual health (physical, emotional, mental and social factors) based on a non-systematic review of scientific (PubMed), empirical and popular literature (eg, online forums, blogs) on this topic. This process resulted in an initial set of 48 statements.

To evaluate its comprehensibility and comprehensiveness, the set was discussed with five male patients diagnosed with IA, one expert in the field of reproductive rheumatology (RJED) and two experts in the field of sexology (HP and JMB). In addition, one expert in the field of Q-methodology (JvE) was consulted to provide methodological advice on the selection and formulation of statements. Following these discussions, a number of adjustments were made: some statements were excluded from the initial set because they covered similar topics (see online supplemental table 2) and the wording of several statements was revised. At the end of this phase, a draft set of 34 statements remained for pilot testing.

To ensure the comprehensiveness and comprehensibility of the statement set and other interview materials, a pilot study involving four male patients with IA was conducted. Based on its results, no modifications to the interview materials, including the statement set were deemed necessary. Therefore, the four participants from the pilot study could be retained for the main study. The final statement set (translated into English), is presented in table 1. The original statement set (in Dutch) can be found in online supplemental table 3 .

\section{Data collection}

Participants were invited for an individual interview in the Erasmus MC, which took approximately 1 hour. Because of the impact of the COVID-19 pandemic, five interviews were conducted using online meeting platforms.

Each session was moderated by LFP-G and ER and started with instructions on the sorting of the statements and an explanation of the concept of sexual health as being a comprehensive term that goes beyond the physical act of sex.

Thereafter, participants were presented with the 34 statements printed on cards, in random order, and asked to carefully read all cards. They were asked to consider each statement in relation to the question 'How does arthritis impact your sexual health?' and sort them into three piles representing statements they agreed with, disagreed with and found to be neutral or irrelevant. The participants were then instructed to reread the cards in each pile prior to ranking them on the sorting grid. They started with the agree pile, followed by the disagree pile and finally the neutral pile (see figure 2).

After ranking the statements, participants were asked open-ended questions. They were asked to explain the placement of certain statements on the sorting grid and all participants elaborated on the two statements with which they most agreed and disagreed. Also, they were invited to discuss any statement they found interesting. At the end of the interview, participants were asked to briefly describe their opinion about the overall impact of IA on their sexual health in their own words. The interviews were voice recorded.

Finally, participants were asked to fill in a questionnaire, which included questions regarding their demographic characteristics, disease activity scores (Health Assessment Questionnaire-Disability Index (HAQ-DI), Rheumatoid Arthritis Disease Activity Index (RADAI), Visual Analogue Scale (VAS)-general health, VAS-disease activity, VAS-pain, VAS-fatigue) and the Patient Health Questionnaire-9 (PHQ-9) for depression screening.

Participants received financial compensation for their travel and parking costs.

\section{Statistical analysis}

Individual statement rankings were subject to by-person factor analysis (ie, centroid factor extraction, followed by varimax rotation) using PQMethod V.2.35. Identified factors, with eigenvalue larger than one and at least two participants significantly associated $(p<0.05)$, were interpreted as viewpoints on the overall effect of IA on male sexual health. Interpretations were based on composite (ie, weighted average) statement rankings for each factor. Inspection of statistical information (ie, explained variance and number of defining variables per factor) and the coherence and interpretability of the factors, also consulting the qualitative materials collected during the interviews, resulted in the choice for a three-factor solution. Consensus statements (ie, those whose rankings did not differ significantly between any pair of viewpoints) and distinguishing statements (ie, those whose rankings in one viewpoint differed significantly from those in all other viewpoints) were identified.

The interpretation and description of each viewpoint were supplemented with the answers to the open-ended questions from participants whose rankings were associated with that viewpoint $(\mathrm{p}<0.05)$.

\section{RESULTS}

Forty-seven men were invited to participate in the study. The final sample consisted of 30 men with IA (response rate of 64\%). Their mean age was 43.2 (range 22-77) years and had a mean disease duration of 15.25 (SD 10.88) years. Most of the participants were Dutch $(86.6 \%)$, sexually active during the last year $(92.8 \%)$ and 
Table 1 Composite ranking of statements for each viewpoint

\begin{tabular}{|c|c|c|c|c|}
\hline \multicolumn{2}{|c|}{ Statement } & \multirow{2}{*}{$\begin{array}{l}\text { 'Arthritis negatively } \\
\text { affects my sex life' } \\
-2^{\star \star}\end{array}$} & \multirow{2}{*}{$\begin{array}{l}\text { ‘I am keeping up } \\
\text { appearances’ } \\
+3^{\star \star}\end{array}$} & \multirow{2}{*}{$\begin{array}{l}\text { ‘I am satisfied with my } \\
\text { sex life’ } \\
+4^{\star \star}\end{array}$} \\
\hline 1 & I am satisfied with my sex life $¥ \S ી$ & & & \\
\hline 2 & Sex is important to my quality of life $\neq$ & $0^{\star \star}$ & +3 & +4 \\
\hline 3 & I enjoy sex less because of my arthritis & -1 & +1 & -1 \\
\hline 4 & My sex life has changed because of my arthritis $¥ \S \rrbracket$ & $0^{*}$ & $+2^{*}$ & $-1^{\star \star}$ \\
\hline 5 & I have sex less frequently because of my arthritis? & +1 & +1 & $-1^{\star \star}$ \\
\hline 6 & $\begin{array}{l}\text { Pain caused by my arthritis has a negative impact on my sex } \\
\text { life }\end{array}$ & +4 & +4 & $+1^{\star \star}$ \\
\hline 7 & Fatigue has a negative impact on my sex life§ & +4 & $0^{* *}$ & +3 \\
\hline 8 & Gloom has a negative impact on my sex life§ & +2 & $-1^{\star \star}$ & +3 \\
\hline 9 & Sex has become less spontaneous due to my arthritis & +2 & +1 & $-1^{\star \star}$ \\
\hline 10 & $\begin{array}{l}\text { I find it difficult that fluctuations in the severity of my illness } \\
\text { make my sex life unpredictablef }\end{array}$ & $+3^{\star \star}$ & -1 & 0 \\
\hline 11 & $\begin{array}{l}\text { My sexual problems are the same as those present in healthy } \\
\text { men‡§ף }\end{array}$ & $-4^{\star \star}$ & $0^{\star *}$ & $+3^{\star \star}$ \\
\hline 12 & I have fewer sexual thoughts because of my arthritis & -3 & -2 & -2 \\
\hline 13 & It is more difficult to get aroused because of my arthritis & -1 & -1 & $-3^{*}$ \\
\hline 14 & My sexual desire is reduced because of my arthritis $\dagger$ & -2 & -1 & -2 \\
\hline 15 & $\begin{array}{l}\text { There are things I would like to do during sex (postures/ } \\
\text { movements) that I cannot do because of my illness } ₫ \S 9\end{array}$ & $+3^{\star *}$ & $+1^{\star *}$ & $0^{* *}$ \\
\hline 16 & $\begin{array}{l}\text { I have trouble getting and/or keeping an erection due to my } \\
\text { arthritisł }\end{array}$ & $+1^{\star \star}$ & -4 & -4 \\
\hline 17 & $\begin{array}{l}\text { I don't want to start having sex because I am afraid that I will } \\
\text { have to stop halfway through my arthritis } \ddagger\end{array}$ & $0^{\star \star}$ & -2 & -2 \\
\hline 18 & I am having problems masturbating due to my arthritis & -3 & -3 & -1 \\
\hline 19 & I feel less masculine because of my arthritis $\mid$ & 0 & -1 & $-2^{\star \star}$ \\
\hline 20 & I feel less attractive because of my arthritis $\mid$ & +1 & +2 & $-3^{\star \star}$ \\
\hline 21 & The physical changes make me feel less confident about sex & +2 & +2 & $0^{\star \star}$ \\
\hline 22 & My sex life must be included in the choice of my treatmentł & $0^{\star \star}$ & +2 & +2 \\
\hline 23 & $\begin{array}{l}\text { I have the need to discuss the effects of my arthritis and } \\
\text { treatment on my sex life with my healthcare providert }\end{array}$ & +1 & 0 & +1 \\
\hline 24 & $\begin{array}{l}\text { I have a hard time talking about my sex life with my healthcare } \\
\text { provider } \neq\end{array}$ & $-1^{\star \star}$ & +1 & +1 \\
\hline 25 & $\begin{array}{l}\text { I prefer to search online for information about the effects of } \\
\text { my arthritis and treatment on my sex life- }\end{array}$ & -1 & 0 & $+2^{*}$ \\
\hline 26 & $\begin{array}{l}\text { I feel like I am the only one with sexual problems caused by } \\
\text { my arthritis } \text { I }\end{array}$ & -2 & -2 & $+1^{\star \star}$ \\
\hline 27 & I find it difficult to discuss sexual problems with a partner§ & -2 & $0^{* *}$ & -3 \\
\hline 28 & My sexual problems make it difficult to be in a relationship & -3 & -3 & $0^{* *}$ \\
\hline 29 & $\begin{array}{l}\text { I feel guilty towards my partner because of the limitations of } \\
\text { my arthritis } \neq\end{array}$ & $+3^{\star \star}$ & 0 & 0 \\
\hline 30 & Intimacy has become more important than sex $\dagger$ & +2 & +3 & +1 \\
\hline 31 & For me, sex is only important if I want a child $\dagger$ & -4 & -4 & -4 \\
\hline 32 & $\begin{array}{l}\text { The relationship with my partner has improved because of my } \\
\text { arthritis }\end{array}$ & -1 & -2 & $+2^{\star \star}$ \\
\hline 33 & My partner understands my sexual problems $¥ \S \rrbracket$ & $+1^{* \star}$ & $+4^{\star *}$ & $+2^{* *}$ \\
\hline 34 & $\begin{array}{l}\text { I sometimes have sex only because I don't want to disappoint } \\
\text { my partner§ }\end{array}$ & 0 & $-3^{\star \star}$ & 0 \\
\hline
\end{tabular}

${ }^{*} p<0.05,{ }^{* *} p<0.01$ versus all other factors.

†Consensus statement.

fDistinguishing statement for viewpoint 1 .

$\S$ Distinguishing statement for viewpoint 2.

qDistinguishing statement for viewpoint 3 . 


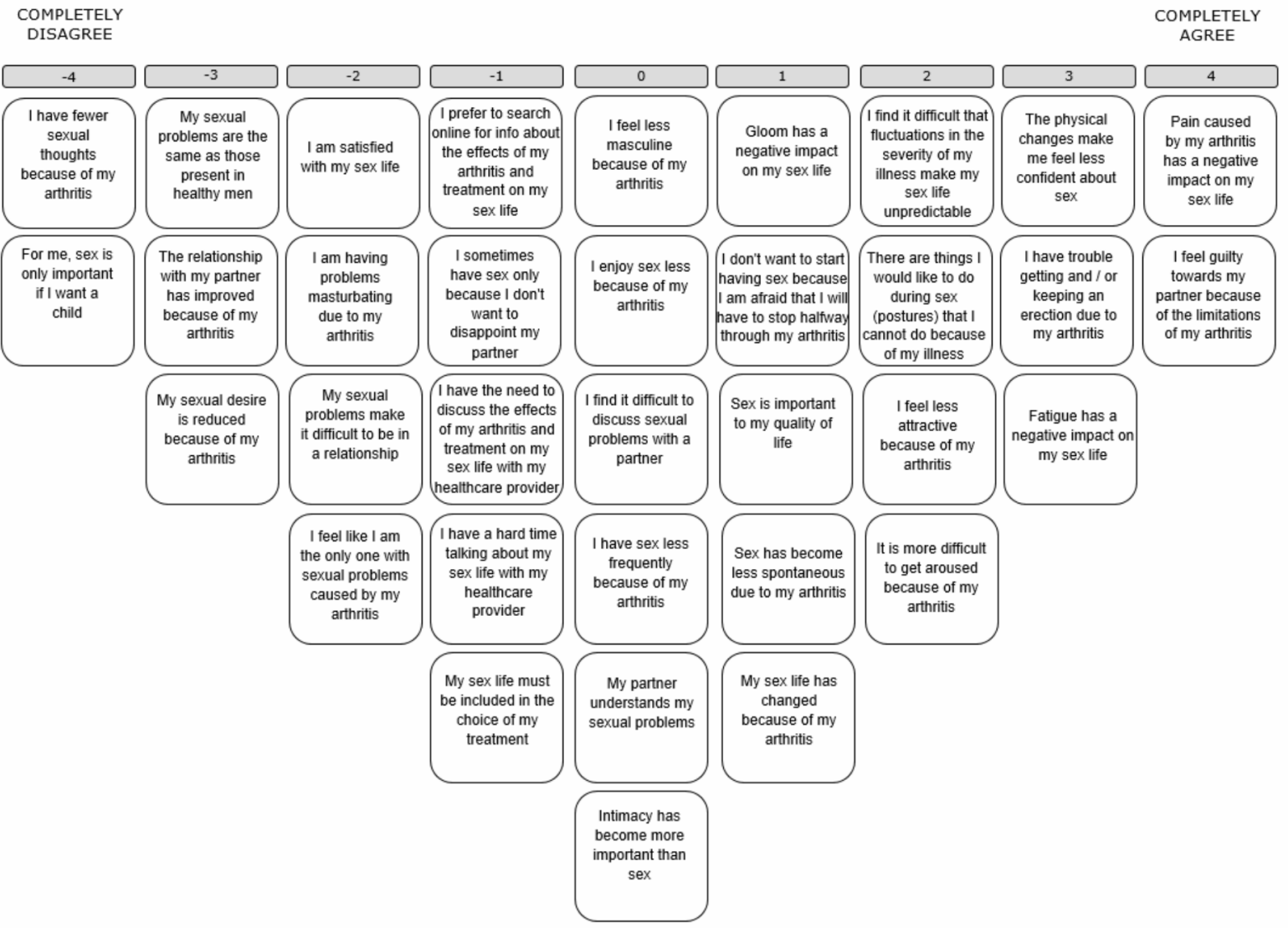

Figure 2 Sorting grid and statements, example of final result. Participants first placed statements with which they agreed with on the right side of the score sheet. They placed the two statements with which they agreed most in the two spots in the extreme right column (+4), followed by the next three statements with which they agreed most (+3) and so on. In the same manner, respondents ranked statements with which they disagreed and those that they found to be neutral on the left side and in the centre of the sorting grid, respectively, until all statements were placed on the sorting grid with only one statement placed in each cell. Participants were encouraged to review the final result and, if necessary, make any changes.

Table 2 Demographic characteristics of participants

\begin{tabular}{|c|c|c|c|c|}
\hline & All participants & $\begin{array}{l}\text { 'Arthritis has a } \\
\text { negative influence on } \\
\text { my sexual health' }\end{array}$ & $\begin{array}{l}\text { 'I am keeping up } \\
\text { appearances' }\end{array}$ & $\begin{array}{l}\text { 'I am satisfied } \\
\text { with my sexual } \\
\text { health' }\end{array}$ \\
\hline Participants, n (\%) & $30(100.00)$ & $6(19.35)$ & $5(16.66)$ & $13(43.33)$ \\
\hline Age, mean (SD) & $42.76(15.50)$ & $36.17(7.60)$ & $43.80(14.02)$ & $43.92(16.27)$ \\
\hline Age at diagnosis, mean (SD) & $27.66(19.76)$ & $15.50(14.71)$ & $28.60(16.72)$ & $31.15(16.29)$ \\
\hline Disease duration years, mean (SD) & $15.25(10.87)$ & $20.67(16.12)$ & $15.20(11.92)$ & $12.77(7.03)$ \\
\hline Religious, n (\%) & $14(46.67)$ & $3(50.00)$ & $2(40.00)$ & $4(30.77)$ \\
\hline Dutch ethnicity, n (\%) & $26(86.67)$ & $6(100.00)$ & $5(100.00)$ & $10(76.92)$ \\
\hline Highly educated, $\mathrm{n}(\%)^{\star}$ & $15(50.00)$ & $1(16.67)$ & $3(75.00)$ & $7(53.85)$ \\
\hline In a relationship, $\mathrm{n}(\%)$ & $29(96.67)$ & $6(100.00)$ & $5(100.00)$ & $12(92.30)$ \\
\hline $\begin{array}{l}\text { Sexual activity last } 12 \text { months, } n \\
(\%) \dagger\end{array}$ & $26(92.86)$ & $6(100.00)$ & $5(100.00)$ & 12 (92.31) \\
\hline Number of children, mean (SD) & $1.16(1.01)$ & $0.50(0.87)$ & $1.40(0.54)$ & $1.15(1.21)$ \\
\hline
\end{tabular}

*Bachelor or University.

†All men who were sexually active reported having had sexual intercourse with women. 
in a relationship (96.6\%). Demographic characteristics of the study population are presented in table 2 .

The analysis revealed three viewpoints. Twenty-four participants were significantly associated with one of these viewpoints $(p<0.05)$. The viewpoints explained $50 \%$ of the variance in the ranking data and table 1 shows the composite rankings of the statements for each of the three viewpoints together with the distinguishing and consensus statements.

\section{Viewpoint 1: 'Arthritis negatively affects my sexual health'}

Men with this viewpoint experience a substantial impact of IA on their sexual health. In particular, pain (st.6:+4; ie, statement 6 receives factor score +4$)$, fatigue (st.7:+4) and gloom (st.8:+2) secondary to IA had a negative influence on their sexual health. They feel unsatisfied with their sexual health (st.1:-2) and consider that their sexual problems are not the same as those present in healthy men (st.11:-4). Due to IA, sex became less spontaneous (st.9:+2), unpredictable (st.10:+3) and difficult (st.15:+3); 'Because of pain, my sex life became more conservative than it was' (45 years, diagnosed with RA at the age of 35).

Although, they acknowledge that IA is associated with problems of getting and/or maintaining an erection (st.16:+1), these men strongly disagreed with the fact that IA reduces their sexual thoughts (st.12:-3), arousal (st.13:-1) and their sexual desire (st.14:-2) indicating that their sexual dysfunction is mainly due to ED and not due to impaired desire and arousal.

The effect that IA has on these men's sexual health also impacts the relationship with their partners. Guilt towards their partners (st.29:+3) and the feeling of not being completely understood by their partners (st.33:+1) could explain why these men feel that their relationship with their partners worsened because of the diagnosis of IA (st.32:-1). As one participant said 'All of my relationship problems are because of my arthritis' (48 years, diagnosed with RA at the age of 44).

With regards to communication, this group of men identified themselves as 'open people'. They find it easy to talk about their sexual health with their partners (st.27:-2) and healthcare professional (st.24:-1). Nonetheless, they expressed that getting access to information regarding this topic was difficult. This was exemplified by one of the most frequently expressed comments: 'My doctor is always busy and has no time for this' (61 years, diagnosed with RA at the age of 42). Finding information online about this topic was considered as 'easy', but not always adequate and therefore not their preferred method to get information (st.25:-1).

Their masculinity (st.19:0) and attractiveness (st.20:+1) were slightly negatively influenced by IA. Notably, this was also associated with a negative effect on their confidence with regards to sex (st.21:+2): 'I have never found myself attractive, I got deformities that no one else got' (48 years, diagnosed with JIA at the age of 1). During the interviews, several men also expressed a feeling of frustration and fear towards the idea of not being the partner and/or the father they would like to be. 'She can get better than me' and 'I'm afraid of not being able to play football with my son' (40 years, diagnosed with RA at the age of 34).

Viewpoint 1 had an eigenvalue ('characteristic value') of 2.94 and explained $10 \%$ of the variance in the ranking data. Six participants $(20 \%)$ were significantly associated with this viewpoint.

\section{Viewpoint 2: 'I am keeping up appearances'}

This group of men also experiences a negative effect of IA on their sexual health. The diagnosis of IA changed their sexual health (st.4:+2). This was mainly due to pain (st.6:+4), which limits their physical abilities (st.15:+1). Furthermore, sex became less frequent $($ st.9:+1) and they enjoy sex less (st.3:+1).

Other factors such as fatigue (st.7:0) and gloom (st.8:-1) were not considered to have negative effects on their sexual health. In addition, IA has no negative effect on their capacity to get or maintain an erection (st.16:-4) or on their sexual desire (st.14:-1), reflecting a pure 'physical/mechanic' negative effect of pain on their sex lives. For these men, sex is considered as important contributor to their quality of life (st.2:+3) and they feel satisfied with their sexual health (st.1:+3).

A distinguishing factor of this group was that these men feel less attractive because of their IA (st.20:+2). During the interviews it became evident that for some men this was directly associated with physical deformities; 'Every day I am thinking about that (his deformities)' (33 years, diagnosed with JIA at the age of 1) or 'It is awkward to get naked in front of your partner when you have swollen joints' (34 years, diagnosed with JIA at the age of 12). For other men, feeling less attractive was associated with their incapacity to perform physical skills (general and during sex), which also has a negative effect on their level of self-confidence.

Another distinguishing factor associated with this group was that these men feel that their partners understand their sexual problems (st.33:+4 and st.34:-3) although it was not always easy for them to discuss these issues with them (st.27:0). The impact of IA on their feelings/beliefs about being a man (masculinity) varied between these men (st.19:-1). During the interviews it became evident that their masculinity is a significant contributor to their quality of life that further defines this viewpoint; 'Being a man is more than just physical, it is also mental, that is why sometimes I don't tell my wife that I am in pain, I am keeping up appearances' (36 years, diagnosed with RA at the age of 35). These men also described they had problems accepting their disease and communicating their sexual health problems to others 'I want to keep everything normal, like it was before' (36 years, diagnosed with RA at the age of 35). As a result, these men tend to hide their problems.

As was the case for viewpoint 1, participants associated with this viewpoint considered that the limited time, 
that rheumatologists have during their regular appointments, was also the most important reason why talking about sexual health with a healthcare provider is difficult (st.24:+1). Currently, most of the participants in this group agreed with the idea that they might not feel the need to discuss this issue with healthcare professionals (st.23:0). However they also indicated that it would have been helpful to receive proper information and advice earlier in their lives.

Viewpoint 2 had an eigenvalue of 1.55 and explained $5 \%$ of the variance. Five participants $(17 \%)$ were significantly associated with this viewpoint.

\section{Viewpoint 3: 'I am satisfied with my sexual health'}

Men with this viewpoint were satisfied with their sexual health (st.1:+4) and considered sex as an important contributor to their quality of life (st.2:+4). In addition, arthritis did not change their sexual health (st.4:-1), had no negative effect on their erectile function (st.16:-4), sexual desire (st.12:-2, st.13:-3 and st.14:-2) or the frequency of sex (st.9:-1).

Gloom and fatigue had the most significant negative influence (st.7:+3 and st.8:+3) on their sexual health. Notably, during the interviews, both statements were mostly defined as being associated with their "normal life' and not specifically with IA. Pain also has a minor negative effect on their sex lives (st.6: +1$)$. Nonetheless, the effect of pain varies between periods of high and low disease activity; 'If I had filled this grid 10 years ago it would have been completely different. Back then, pain had a major effect on my sex life' (62 years, diagnosed with RA at the age of 42).

These men believe that their sexual problems are the same as those present in healthy men (st.11:+3). Furthermore, this statement was also associated with episodes of their lives where they have low disease activity or are in clinical remission; 'I have no pain now and I feel like a healthy man' (31 years, diagnosed with RA at the age of 22) or with certain attitudes towards the disease itself 'I want to be a healthy man' (74 years, diagnosed with RA at the age of 59). Their masculinity and feelings of attractiveness are not (or no longer) significantly impacted by the diagnosis of IA (st.19:-2 and st.20:-3).

Other themes that emerged within this viewpoint were that these men believe that their relationships with their partners improved after receiving the diagnosis of IA (st.32:+2), that their partners understand their sexual problems (st.33:+2) and intimacy became more important than sex (st.30:+1).

Communication with their partners about this topic is not considered to be difficult (st.27:-3); 'The diagnosis of arthritis opened the doors to us discussing other stuff' (36 years, diagnosed with RA at the age of 30). With regards to communication with healthcare professionals (st.24:+1), they prefer to get information about this topic online (st.25:+2).

For these men, it is important to consider their sexual health when taking decisions about their medical treatment (st.22:+2). This was of special importance when these men have an active wish to become a father.

Viewpoint 3 had an eigenvalue of 10.35 and explained $35 \%$ of the variance. Thirteen participants $(43.3 \%)$ were significantly associated with this viewpoint.

Demographic and clinical differences between the viewpoints Although the design of this study was not intended to draw epidemiological conclusions, the differences in the demographic and clinical characteristics of the participants across the three viewpoints are worth mentioning (see tables 2 and 3 ).

One of the most striking differences is that compared with men identified with viewpoints 2 and 3, men

Table 3 Participants' patient reported outcomes (general health, disease activity, pain, fatigue, disability and depression)

\begin{tabular}{|c|c|c|c|c|}
\hline & All participants & $\begin{array}{l}\text { 'Arthritis has a negative } \\
\text { influence on my sexual } \\
\text { health' }\end{array}$ & $\begin{array}{l}\text { ‘I am keeping up } \\
\text { appearances' }\end{array}$ & $\begin{array}{l}\text { 'I am satisfied with my } \\
\text { sexual health’ }\end{array}$ \\
\hline Participants, n (\%) & $30(100.00)$ & $6(19.35)$ & $5(16.66)$ & $13(43.33)$ \\
\hline VAS health, median (SD)* & $3.11(2.32)$ & $5.68(1.62)$ & 3.95 (1.92) & $1.85(1.76)$ \\
\hline VAS activity (SD)* & $3.32(3.22)$ & $4.93(3.93)$ & $4.55(2.17)$ & $2.89(3.34)$ \\
\hline VAS pain $(S D)^{\star}$ & $3.32(3.15)$ & $3.98(3.00)$ & $4.72(1.65)$ & $3.06(3.60)$ \\
\hline VAS fatigue (SD)* & $4.72(2.97)$ & $6.63(2.45)$ & $6.20(1.35)$ & $3.03(2.81)$ \\
\hline HAQ-DI, mean (SD)† & $0.64(0.58)$ & $1.30(0.57)$ & $0.84(0.55)$ & $0.41(0.44)$ \\
\hline RADAI (SD) $\ddagger$ & $2.78(2.33)$ & $3.72(2.76)$ & $3.08(1.29)$ & $2.56(2.53)$ \\
\hline PHQ-9, mean (SD)§ & $4.21(4.56)$ & $7.66(5.75)$ & $3.25(0.50)$ & $4.00(4.77)$ \\
\hline
\end{tabular}

*Score range $0-10$. It is a $10 \mathrm{~cm}$ straight horizontal line in which the ends are defined as the extreme limits of the parameter to be measured (health, disease activity, pain, fatigue) orientated from the 0 (best) to 10 (worst).

†Score range $0-3$. Scores of $0-1$ are considered to represent mild-to-moderate difficulty, 1-2 moderate-to-severe disability and 2-3 severe-to-very severe disability.

$\ddagger$ Score range 0 to 5.4. A RADAl score of 0 means no disease activity; higher scores are indicating higher levels of underlying RA disease activity. Scores between 0 and 1.4 indicate remission, 1.6 and 3.0 low disease activity, 3.2 and 5.4 moderate disease activity, and $>5.6$ high disease activity. §Score range 0 to 27. Depression Severity can be classified as follows: 0-4 none, 5-9 mild, 10-14 moderate, 15-19 moderately severe, 20-27 severe. HAQ-DI, Health Assessement Questionnaire-Disability Index; PHQ-9, Patient Health Questionnaire; RADAl, Rheumatoid Arthritis Disease Activity Index; VAS, Visual Analogue Scale. 
identified with viewpoint 1 received the diagnosis of IA at a younger age (28.6 vs 31.1 vs 15.5 years, respectively).

Furthermore, compared with men associated with viewpoint 3 , men associated with viewpoints 1 and 2 reported higher disease activity. Noteworthy, men associated with viewpoint 1 reported more depressive symptoms while men associated with viewpoint 2 reported higher pain scores (see table 3 ).

\section{DISCUSSION}

Although the WHO has indicated that sexual health goes well beyond the absence of disease ${ }^{1}$ and others have recommended evaluating sexual health using a more holistic approach, ${ }^{17}$ so far the impact of IA on male sexual health has been mainly studied focusing on ED. Using Q-methodology, we addressed these recommendations and identified three viewpoints on the overall impact of IA on male sexual health among adult men in: 'Arthritis negatively affects my sexual health', 'I am keeping up appearances' and 'I am satisfied with my sexual health'.

A negative impact of IA on male sexual health was described in viewpoints 1 and 2. Understanding the different characteristics between these two viewpoints is an important first step towards identifying and approaching these patients.

A severe and 'full' effect of IA on sexual health was identified in viewpoint 1 ("Arthritis negatively affects my sexual health'). Not only were these men characterised by the fact that they clearly attributed their erectile problems to the diagnosis of IA but they also described how multiple characteristics of IA significantly impacted all components of sexual health: physical (pain and fatigue), emotional (feeling guilty towards their partners, lower self-confidence), mental (higher PHQ-9 scores) and social (problems with partners). These men were younger, had a longer disease duration, reported lower general health and had more depressive symptoms. Altogether this might suggest that men diagnosed with IA at an early age might be particularly vulnerable to experience a negative effect of IA on their sexual health. Men with this viewpoint expressed their willingness to talk about and seek help concerning their sexual health problems.

In contrast, men with viewpoint 2 ('I am keeping up appearances') experience milder and mainly physical sexual problems. These problems were mainly associated with pain and were considered a difficult topic to discuss. Although they indicated that IA changed their sexual life and they enjoy sex less because of the diagnosis of IA, these men also agreed with the statement that they feel satisfied with their sexual health. A potential explanation for this discrepancy in the quantitative data was provided by the men during the interviews. These qualitative data revealed a stronger and more complex negative effect of IA on male sexual health and a distinguishing coping mechanism that these men have in relation to the diagnosis of IA and/or living with IA. Compared with women, men with RA struggle more often to accept and cope with their diagnosis. ${ }^{18-20}$ Using Q-methodology, two different coping strategies in men with RA were previously described; 'acknowledge, accept and adapt' and 'trying to match up to a macho ideal'. ${ }^{21}$ Men with viewpoint 2 share many distinguishing factors with the coping strategy 'trying to match up to a macho ideal', which further supports the theory that some men tend to hide their feelings of vulnerability ('I am a man'). This attitude may result in difficulties for healthcare professionals to address the needs of their patients adequately, as they may miss important internal distress experienced by their patients. Therefore, identifying these men can be considered a challenge and requires a special approach. Instead of asking them whether they feel satisfied with their sexual health or if they have sexual health problems (ie, erectile dysfunction), these men are more receptive to questions such as; did IA change your sexual health? or, is IA interfering with your ability to enjoy sex?

Men with viewpoint 3 ('I am satisfied with my sexual health') indicated that they were satisfied with their sexual health and considered their sexual health problems as not being different from those of healthy men. These men associated their degree of satisfaction with their current states of clinical remission or low disease activity. Their interviews provided us with an important message about the potential dynamics of the viewpoints. Participants described how ranking the statements would have been different if they participated during a period with higher disease activity. In the past, during such periods IA did impair their sexual health, which resulted in dissatisfaction. This was usually solved when low disease activity or remission was achieved. With this regard, it has been previously reported that improvement in disease activity has been associated with improved sexual function ${ }^{22}$ and with a better quality of life. ${ }^{23}$

Participants across the three viewpoints also pointed out that their ranking of the statements would have been different if they would have participated during a different phase of their life (ie, adolescence/young adulthood). As an example, men who were diagnosed at a younger age described how exploring their sexuality was difficult and different compared with 'other boys', how their diagnosis led to problems in their relationships during their early dating years. They also described longterm consequences of the diagnosis of IA, for instance how IA interfered with their sexual development and how certain bodily malformations secondary to IA can have a long-lasting significant psychological impact on their daily lives.

In general, and similar to other chronic conditions, ${ }^{24-26}$ there was broad consensus among participants that independent of their age or health perception, sexual health is an important contributor to their quality of life. Furthermore, most participants agreed that sexual health is not only important when having an active desire to become a father. Most patients disclosed that receiving information and advice about sexual health in relation 
to their IA would have been helpful. They also reflected on the importance of approaching sexual health during different phases of life as well as different stages of the disease itself. This has also been reported for similar chronic musculoskeletal conditions affecting sexual health. ${ }^{27}$ They were open to discuss sexual health with their healthcare professionals, but this issue was hardly ever raised by healthcare professionals.

Several explanations for this communication gap between healthcare professionals and patients have been described. ${ }^{28}$ First, healthcare professionals generally incorrectly believe that sexual health is not as crucial as other topics or that patients do not expect them to discuss sexual concerns. ${ }^{29}$ Notwithstanding, as an important contributor to the quality of life of men with IA, and in line with recommendations, ${ }^{30}$ male sexual health should be periodically raised by healthcare professionals in consultations with their patients. As it has been reported in the literature, it is important to consider that the majority of patients prefers active inquiry about sexual health from their healthcare professionals. ${ }^{31}$ Concerning this, most participants expressed their gratitude to the research team for 'starting the conversation' by inviting them to take part in the study. They described how participating in this study was a positive experience that allowed them to better understand how IA had impacted (or not) their sexual health, and lead them to discuss this topic with their partners.

Second, limited time during the consultation was described as one of the most important barriers to discuss this topic with healthcare professionals. Increased awareness of this problem, pre-consultation questionnaires for patients and a dedicated teamwork effort between all healthcare professionals involved in the care of men with IA (General practitioners, rheumatologists, nurses, psychologists, sexologists, etc) can result in an efficient method to approach this topic.

Lastly, another important barrier is that healthcare professionals often feel unprepared or lack the necessary knowledge to raise and discuss this topic with their patients. ${ }^{32}$ The Permission, Limited, Information, Specific Suggestions and Intensive Therapy model can be used by healthcare professionals to facilitate their evaluation of sexual health. ${ }^{33} 34$ Importantly, sexual health assessment (in the clinic and in research) should be broad and not only focus on the presence or absence of erectile dysfunction. Tailor-made educational programmes about sexual health should be designed and disseminated among healthcare professionals in the field of rheumatology.

Our study has several strengths. By combining qualitative and qualitative data using Q-methodology we were able to describe the impact of IA on many components of sexual health. This allowed us to identify multiple characteristics that could have been easily missed by conventional questionnaires or screening tools and that were crucial to understand the impact of IA on male sexual health and that are relevant for the patients and their quality of life. Furthermore, to ensure a representative and relevant outcome, a multidisciplinary approach that included the input from patients and experts from several fields was used during the design, conduction and interpretation of the study.

An important limitation of this study is that the group of men included was not as diverse as the general population of men with IA. In particular, single men, of non-Dutch ethnic background, non-heterosexual and devout or very religious were difficult to recruit. In addition, the response rate of $64 \%$, although higher than expected, does not exclude the possibility of having missed participants with communication problems or who specifically did not want to talk about sexual health. This means that additional viewpoints, particular to these groups, may have been missed. Moreover, this study was conducted in the Netherlands and the findings are thus confined to the specific sociocultural and healthcare system characteristics in this country. Similar studies in other countries may reveal partly different viewpoints, with insights that are relevant in their specific patient population and clinical and social context. Replication is therefore recommended, after careful consideration of the comprehensiveness of the set of statements for local use. Although the results of this study are not generalisable to different populations, they do highlight that research into this topic and raising issues with sexual health in clinical practice may be relevant in other populations as well.

Future research should focus on identifying the prevalence of the three viewpoints in a larger population and better characterising the clinical characteristics and predictors of impaired sexual health in men with IA. Furthermore, prospective studies on whether and to what extent these viewpoints change in association with disease activity and duration, antirheumatic therapy and/or the patients' age are encouraged. Ideally, such studies will provide us with enough information to elaborate questionnaires or diagnostic tools that can facilitate the identification of patients with IA and impaired sexual health. Moreover, the development of efficient intervention strategies to prevent and treat sexual health problems in men with IA are needed. To this end, multidisciplinary collaboration with fields such as sexology, psychology and andrology is recommended. Establishing these research strategies will not only result in an increased awareness of this problem among the rheumatology community but can also stimulate healthcare professionals to 'start the conversation' and to talk about sexual health with their patients.

Our study confirms that sexual health is important for men with IA and that the overall impact of IA on their sexual health is significant and goes well beyond erectile problems.

\section{Twitter Luis Fernando Perez-Garcia @DrReumatologo}

Contributors All authors met the authorship criteria, they had a substantial contribution to the conception or design of the work (all authors) or the acquisition (LFP-G, ER and RJED), analysis (LFP-G, ER, JvE and RJED) or interpretation of data for the work (all authors) and were involved in revising a draft of this work, gave final approval of this version to be published and are accountable for all aspects of the work in ensuring accuracy and integrity.

Funding This work was supported by research grants from the Dutch Arthritis Foundation (ReumaNederland) (project number: 16-3-402), ZonMw (project number 849200009) and Consejo Nacional de Ciencia y Tecnologia (CONACYT) (project number 601574). All are non-profit organisations. 
Competing interests LFP-G Consultant of: Galapagos, ER: None declared, HP: None declared, JMB: None declared, JvE: None declared, RJED Speakers bureau: UCB, Roche, AbbVie, Genzyme, Novartis, Consultant of: Galapagos, Grant/research support from: UCB.

Patient consent for publication Consent obtained directly from patient(s) Ethics approval This study was reviewed by the Medical Ethics Committee of the Erasmus University Medical Centre. The committee declared that the rules laid down in the Medical Research Involving Human Subjects Act do not apply to this study. Written informed consent was obtained from all participants.

Provenance and peer review Not commissioned; externally peer reviewed.

Data availability statement All data relevant to the study are included in the article or uploaded as supplementary information.

Open access This is an open access article distributed in accordance with the Creative Commons Attribution Non Commercial (CC BY-NC 4.0) license, which permits others to distribute, remix, adapt, build upon this work non-commercially, and license their derivative works on different terms, provided the original work is properly cited, appropriate credit is given, any changes made indicated, and the use is non-commercial. See: http://creativecommons.org/licenses/by-nc/4.0/.

ORCID iDs

Luis Fernando Perez-Garcia http://orcid.org/0000-0002-8958-9493

Esther Röder http://orcid.org/0000-0003-2139-3838

\section{REFERENCES}

1 Organization WH. Measuring sexual health: conceptual and practical considerations and related indicators. Geneva, Switzerland: WHO publications, 2010.

2 Perez-Garcia LF, Te Winkel B, Carrizales JP, et al. Sexual function and reproduction can be impaired in men with rheumatic diseases: a systematic review. Semin Arthritis Rheum 2020;50:557-73.

3 Bay LT, Graugaard C, Nielsen DS, et al. Sexual health and dysfunction in patients with rheumatoid arthritis: a cross-sectional single-center study. Sex Med 2020;8:615-30.

4 Hill J, Bird H, Thorpe R. Effects of rheumatoid arthritis on sexual activity and relationships. Rheumatology 2003;42:280-6.

5 Frith $\mathrm{H}$. Focusing on sex: using focus groups in sex research. Sexualities 2000;3:275-97.

6 Van Exel J. De Graaf G. Q methodology: a sneak preview. online document available from, 2005. Available: http://wwwqmethodorg

7 Watts S, Stenner P. Doing Q methodological research: theory, method and interpretation. London2012. available from:. Available: https://methods.sagepub.com/book/doing-q-methodologicalresearch

8 Watts S, Stenner P. Doing Q ethodology: theory, method and interpretation. Qual Res Psychol 2005;2:67-91.

9 Cross RM. Exploring attitudes: the case for Q methodology. Health Educ Res 2005;20:206-13.

10 Patty NJS, van Dijk HM, Wallenburg I, et al. To vaccinate or not to vaccinate? perspectives on HPV vaccination among girls, boys, and parents in the Netherlands: a Q-methodological study. BMC Public Health 2017:17:872.

11 Truijens D, van Exel J. Views on deceased organ donation in the Netherlands: a q-methodology study. PLoS One 2019;14:e0216479.

12 Galekop MMJ, van Dijk HM, van Exel J, et al. Views of professionals and volunteers in palliative care on patient-centred care: a Q-methodology study in the Netherlands. BMC Palliat Care 2019;18:97.

13 Cramm JM, Leensvaart L, Berghout M, et al. Exploring views on what is important for patient-centred care in end-stage renal disease using $Q$ methodology. BMC Nephrol 2015;16:74.
14 Churruca K, Ludlow K, Wu W, et al. A scoping review of Q-methodology in healthcare research. BMC Med Res Methodol 2021;21:125.

15 Ferrari S, Vanti C, Giagio S, et al. Low back pain and sexual disability from the patient's perspective: a qualitative study. Disabil Rehabil 2020:1-9.

16 Perez-Garcia LF, Dolhain R, Te Winkel B, et al. Male sexual health and reproduction in cutaneous immune-mediated diseases: a systematic review. Sex Med Rev 2021;9:423-433.

17 Douglas JM, Fenton KA. Understanding sexual health and its role in more effective prevention programs. Public Health Rep 2013;128 Suppl $1: 1-4$.

18 Flurey C, White A, Rodham K, et al. 'Everyone assumes a man to be quite strong': men, masculinity and rheumatoid arthritis: a case-study approach. Sociol Health IIIn 2018;40:115-29.

19 Flurey CA, Hewlett S, Rodham K, et al. Men, rheumatoid arthritis, psychosocial impact and self-management: a narrative review. $J$ Health Psychol 2016;21:2168-82.

20 Flurey CA, Hewlett S, Rodham K, et al. Coping strategies, psychological impact, and support preferences of men with rheumatoid arthritis: a multicenter survey. Arthritis Care Res 2018;70:851-60.

21 Flurey CA, Hewlett S, Rodham K, et al. Identifying different typologies of experiences and coping strategies in men with rheumatoid arthritis: a Q-methodology study. BMJ Open 2016;6:e012051.

22 P-G, Micu MC LF, Gheyle L, Yin Z, et al. Sexual function in male and female patients with rheumatoid arthritis: a post-hoc analysis of the finch studies. Ann Rheum Dis 2021;80:496.

23 Scott IC, Ibrahim F, Lewis CM, et al. Impact of intensive treatment and remission on health-related quality of life in early and established rheumatoid arthritis. RMD Open 2016;2:e000270.

24 Flynn KE, Lin L, Bruner DW, et al. Sexual satisfaction and the importance of sexual health to quality of life throughout the life course of U.S. adults. J Sex Med 2016;13:1642-50.

25 Lu Y, Fan S, Cui J, et al. The decline in sexual function, psychological disorders (anxiety and depression) and life satisfaction in older men: a cross-sectional study in a hospital-based population. Andrologia 2020;52:e13559.

26 Buczak-Stec E, König H-H, Hajek A. The link between sexual satisfaction and subjective well-being: a longitudinal perspective based on the German ageing survey. Qual Life Res 2019;28:3025-35.

27 Nilsing Strid E, Ekelius-Hamping M. Experiences of sexual health in persons with hip and knee osteoarthritis: a qualitative study. BMC Musculoskelet Disord 2020;21:576.

28 Dyer K, das Nair R. Why don't healthcare professionals talk about sex? A systematic review of recent qualitative studies conducted in the United kingdom. J Sex Med 2013;10:2658-70.

29 Zhang X, Sherman L, Foster M. Patients' and providers' perspectives on sexual health discussion in the United States: a scoping review. Patient Educ Couns 2020;103:2205-13.

30 Matcham F, Scott IC, Rayner L, et al. The impact of rheumatoid arthritis on quality-of-life assessed using the SF-36: a systematic review and meta-analysis. Semin Arthritis Rheum 2014;44:123-30.

31 Ryan KL, Arbuckle-Bernstein V, Smith G, et al. Let's talk about sex: a survey of patients' preferences when addressing sexual health concerns in a family medicine residency program office. PRIMER 2018;2:23.

32 Merrill JM, Laux LF, Thornby JI. Why doctors have difficulty with sex histories. South Med J 1990;83:613-7.

33 Albaugh JA, Kellogg-Spadt S. Sexuality and sexual health: the nurse's role and initial approach to patients. Urol Nurs 2003;23:227-8.

34 Annon JS. The PLISSIT model: a proposed conceptual scheme for the behavioral treatment of sexual problems. J Sex Educ Ther 1976;2:1-15. 